\title{
Weight gain in the first two years of life, asthma and atopy: the SCAALA cohort study
}

\author{
Sheila MA Matos ${ }^{1, *}$, Sandra R Jesus², Silvia RDM Saldiva ${ }^{3}$, Matildes S Prado', Silvana \\ $D^{\prime}$ Innocenzo ${ }^{1}$, Ana MO Assis ${ }^{4}$, Laura C Rodrigues ${ }^{5}$, Neuza M Alcantara-Neves ${ }^{6}$, \\ Álvaro A Cruz ${ }^{7}$, Silvia de Magalhães Simões ${ }^{8}$, Rosemeire L Fiaccone ${ }^{9}$ and Maurício L \\ Barreto ${ }^{1}$ \\ 'Institute of Collective Health, Federal University of Bahia, Rua Basílio da Gama s/n , Campus Universitário do \\ Canela, $5^{\circ}$ andar, 401 10-040 Salvador, Bahia, Brazil: 2Division of Epidemiology and Collective Health, \\ Multidisciplinary Health Unit, Federal University of Bahia, Salvador, Bahia, Brazil: ${ }^{3}$ Institute of Health, São Paulo \\ State Department of Health, São Paulo, São Paulo, Brazil: ${ }^{4}$ School of Nutrition, Federal University of Bahia, \\ Salvador, Bahia, Brazil: ${ }^{5}$ Department of Epidemiology and Population Health, London School of Hygiene and \\ Tropical Medicine, London, UK: ${ }^{6}$ Health Sciences Institute, Federal University of Bahia, Salvador, Bahia, Brazil: \\ ${ }^{7}$ ProAR, School of Medicine, Federal University of Bahia, Salvador, Bahia, Brazil: ${ }^{8}$ Center for Biological and \\ Health Sciences, Department of Medicine, Federal University of Sergipe, Aracaju, Sergipe, Brazil: ${ }^{9}$ Statistics \\ Department, Federal University of Bahia, Salvador, Bahia, Brazil
}

Submitted 22 January 2013: Final revision received 30 June 2013: Accepted 23 September 2013: First published online 280 October 2013

\begin{abstract}
Objective: To evaluate the association between weight gain in the first two years of life and the occurrence of wheezing, asthma, serum IgE, skin reactivity and pulmonary function.

Design: Cohort study.

Setting: The metropolitan region of Salvador, Bahia, Brazil.

Subjects: The association was studied between 1997 and 2005 in 669 children up to 11 years of age. Data were collected on asthma and risk factors, both current factors and those present in the first years of life. Weight gain was considered fast when the $Z$-score was $>0 \cdot 67$. Poisson regression was used in the multivariate statistical analysis.

Results: Wheezing was reported in $25.6 \%$ of the children. Weight gain was considered fast $(Z$-score $>0.67$ ) in $29.6 \%$ of the children and slow ( $Z$-score $<-0.67)$ in $13.9 \%$. Children in the slow weight gain group had $36 \%$ fewer symptoms of asthma (prevalence ratio $=0 \cdot 65 ; 95 \%$ CI $0 \cdot 42,0 \cdot 99$ ).

Conclusions: Slower weight gain in the early years of life may constitute a protective factor against symptoms of asthma. The relevance of this finding for public health is not yet certain, since it is known that children with slow and fast weight gain may be more likely to develop adverse health consequences related to both these situations.
\end{abstract}

\author{
Keywords \\ Weight gain \\ Children \\ Asthma \\ Atopy \\ Pulmonary function
}

Fast weight gain in the first year of life has been suggested to be a potential risk factor for the occurrence of obesity and chronic diseases in childhood ${ }^{(1)}$ and adulthood ${ }^{(2)}$, and considered to be evidence in support of the fetal origins of disease hypothesis (the Barker hypothesis), which suggests that conditions during fetal life and early childhood may increase the risk of chronic diseases in adults $^{(2,3)}$

There is also evidence that infants with low birth weight, whose postnatal catch-up growth is rapid, are more likely to become overweight or obese as children ${ }^{(1,4)}$. Another highly debated association $^{(5)}$ is that between asthma and obesity, as is the relationship between low birth weight and impaired pulmonary function ${ }^{(6)}$. Nevertheless, the few studies that have investigated the relationship between the speed of weight gain in early life and the occurrence of asthma, allergies and impaired pulmonary function have yielded inconclusive results ${ }^{(7)}$. Birth weight above $4500 \mathrm{~g}$ has been shown to be both a risk and a protective factor for the development of asthma in childhood ${ }^{(8)}$. There is evidence that in adults, poorer weight gain in the early years of life may be related to a slight decrease in pulmonary function, and lung volume and diffusing capacity increase by $2-4 \%$ when birth weight increases by $30 \%{ }^{(9)}$. Nevertheless, at 5-14 weeks after birth, impairment in pulmonary function was found to be worse in infants whose postnatal weight gain was greater (highest tertile) $^{(10)}$. 
The objective of the present study was to estimate the association between weight gain in the first two years of life and the occurrence of wheezing, asthma symptoms, serum IgE levels and pulmonary function in children aged 4-11 years. To our knowledge, no published study has yet been able to demonstrate an association between weight gain during infancy and the occurrence of asthma symptoms and atopy at school age.

\section{Methods}

\section{Study area and population}

The current cohort study (SCAALA) was conducted in Salvador, a city located in the north-east of Brazil. The participants included in the study were derived from three sequential cohorts recruited during the periods 1997, 2000 and 2003 to evaluate the impact of the introduction of a basic sanitation programme on the occurrence of diarrhoea in children between 0 and 3 years of age recruited from twenty-four small geographical areas (called sentinel areas) selected to represent the population without sanitation in the poorest neighbourhoods of Salvador. Data on study outcomes were collected in 2005 when the children were aged 4-11 years. Data collection was done by a project team from the Instituto de Saude Coletiva during all phases of the study. A detailed description of the study design and methods is provided elsewhere $^{(11,12)}$. In the present analysis, we used a subsample of the cohort that included only children born between 1994 and 2001 who were aged less than 24 months at the start of the initial cohort study.

\section{Data collection}

All children aged between birth and less than 24 months at baseline were weighed up to three times at intervals of 6 months where possible. At least one measurement in addition to the birth measurement was done before 24 months ${ }^{(12)}$. Each measurement was taken in duplicate independently by trained nutritionists and the final weight was the mean of the two measurements ${ }^{(13)}$. Where there was more than one measurement for a child, the one nearest to 24 months of age was used in the current analysis. Children were weighed using portable electronic micro scales (Filizola ${ }^{\circledR}$, model E-150/3P, São Paulo, Brazil) with a $150 \mathrm{~kg}$ capacity and accurate to within $100 \mathrm{~g}$. Data for a child's date of birth and birth weight were extracted from the birth certificate. To calculate the $Z$-score for the weight gain between birth and up to 24 months of age, the WHO's reference curve for children up to 5 years of age was used, taking into consideration age and gender, using the following formula:

$$
\text { Weight gain } Z \text {-score }=\frac{\left(X_{2}-X_{1}\right)-\left(Y_{2}-Y_{1}\right)}{\sqrt{S_{Y_{2}}^{2}+S_{Y_{1}}^{2}}},
$$

in which $X_{2}$ is the measured weight of the child; $X_{1}$ is the child's birth weight; $Y_{2}$ is the reference weight; $Y_{1}$ is the reference birth weight; $S_{Y_{2}}^{2}$ is the variation between the child's birth weight and the reference birth weight for gender and age; and $S_{Y_{1}}^{2}$ is the variation between the child's weight and the reference weight for gender and age. Weight gain was considered fast when the $Z$-score was $>0 \cdot 67$. This cut-off point was based on a system proposed by Ong et al. ${ }^{(1)}$ and has been used by other investigators $^{(14,15)}$. In the present analysis, weight gain was considered normal when $Z$-scores were between -0.67 and 0.67 and slow when Z-scores were $<-0.67$.

Height and weight were measured for each child in 2005 using standard procedures ${ }^{(13)}$. BMI was calculated and analysed in 2009 using the 2006 and 2007 WHO reference standards.

Socio-economic and environmental data and information on asthma symptoms were obtained in 2005 using a standardized questionnaire adapted from the Portuguese version of the ISAAC (International Study of Asthma and Allergies in Childhood) Phase II questionnaire ${ }^{(16)}$.

Data on the occurrence of diarrhoea were collected during twice-weekly visits with the use of questionnaires that were completed during interviews with the children's mothers or caregivers. The data obtained referred to the 3-4 d preceding the interview. A day of diarrhoea was defined as the occurrence of three more watery or soft stools within a $24 \mathrm{~h}$ period, and a diarrhoea episode was identified by a minimum $3 \mathrm{~d}$ diarrhoea-free gap (following our definition of day of diarrhoea) to mark the beginning of a new episode. The study end point was the duration of episodes, defined as a continuous variable.

Skin tests were performed on the right forearm of each child using extracts (ALK-Abello, São Paulo, Brazil) of the following allergens: cat epithelium, dog epithelium, Dermatophagoides pteronyssinus (house dust mite), Blomia tropicalis (tropical dust mite), Blattella germanica (German cockroach), Periplaneta americana (American cockroach) and a fungi mix. Saline solution and histamine were used as negative and positive controls, respectively $^{(16)}$. Wheal sizes were read after $15 \mathrm{~min}$ and the test was considered positive if the mean of the two perpendicular diameters was at least $3 \mathrm{~mm}$ larger than that of the negative controls. Skin prick test reactivity was considered positive when there was at least one positive response to any of the allergens tested.

Blood samples were collected for measurements of allergen-specific IgE for $P$. americana, D. pteronyssinus, $B$. tropicalis and B. germanica using commercial ImmunoCAP kits (Pharmacia Diagnostic, Uppsala, Sweden). For the purposes of the present analysis, the presence of allergen-specific IgE in each child was defined as $0=$ non detectable $(<0 \cdot 35 \mathrm{kU} / \mathrm{l})$ and $1=$ detectable $(\geq 0 \cdot 35 \mathrm{kU} / \mathrm{l})$.

Spirometry was performed in accordance with the recommendations of the American Thoracic Society ${ }^{(17)}$, using a Koko ${ }^{\circledR}$ spirometer. The volumes measured were 
forced vital capacity (FVC) and forced expiratory volume in $1 \mathrm{~s}\left(\mathrm{FEV}_{1}\right)$. A bronchodilation test was performed by inhaling salbutamol $200 \mu \mathrm{g}$ with spirometry being repeated after $15 \mathrm{~min}$. A positive response to the bronchodilator was an increase of $\geq 12 \%$ and $\geq 200 \mathrm{ml}$ in $\mathrm{FEV}_{1}$ value compared with before inhalation of the short-acting $\beta_{2}$ agonist $^{(18)}$. The program used by the spirometer automatically calculated the forced expiratory ratio $\left(\mathrm{FEV}_{1}: \mathrm{FVC}\right)$ and provided predicted values for each participant in accordance with the Brazilian standard curve, taking into account the age, sex, weight and height of the child ${ }^{(19)}$. Pulmonary function was not evaluated in children below 6 years of age. Per cent predicted values ranged from 74 to $110 \%$ with a mean of $98 \%$. Since only two children had predicted $\mathrm{FEV}_{1}$ :FVC value below normal (<80\%), 98\% was used as the cut-off to define the outcome variable for pulmonary function.

Current asthma was defined as the reported occurrence of wheezing in the last 12 months and a positive response to at least one of the following: asthma at some time in the child's life, asthma in the previous 12 months, waking up at night because of wheezing, wheezing during/after exercise and four or more episodes of wheezing.

\section{Statistical analyses}

Univariate and multivariate analyses were performed using Poisson regression to assess the relationship between exposure and outcomes. Since the study outcomes (allergen skin test reactivity, serum IgE, $\mathrm{FEV}_{1}$ :FVC, wheezing in the previous 12 months and asthma symptoms) were not rare events, overestimation of the odds ratio may be observed as compared with the prevalence ratio (PR). Therefore, rather than using logistic regression, multivariate Poisson regression models were defined with robust variance ${ }^{(20)}$ that adjusted for all variables that were statistically significant at $P<0 \cdot 05$. The association between weight gain and outcomes controlled for the $a$ priori confounders of sex, child's age, maternal educational level and parental asthma. Other variables evaluated in the models were: mould in the house in the first year of life, household pets, number of persons per room, paving in the street, birth weight, duration of breastfeeding, number of older siblings and BMI. Backwards stepwise selection was then done and variables with $P<0.05$ were excluded. Variables were kept in each model if they were observed to change the effect estimates for speed of growth and the main risk factor of interest in each model by more than $10 \%$, regardless of significance $^{(21)}$.

Likelihood ratio tests were used to evaluate interactions and were considered to be present with $P<0 \cdot 10^{(21)}$. According to our conceptual model, birth weight, duration of breast-feeding and age were considered to be potential effect modifiers. Differences between mean $Z$-scores for weight gain for study outcomes were assessed using Student's $t$ test. Data were entered into Epi-Info version
6.4 and analysed using the statistical software package STATA version $9 \cdot 0$.

Ethical approval for the study was obtained from the Instituto de Saude Coletiva, Universidade Federal de Bahia, and written informed consent was obtained from the legal guardian of each child.

\section{Results}

Of 759 children aged 4-11 years assessed in 2005(16), 669 who had complete data including data to allow measurement of growth during the first two years were included in the present analysis. The mean of age of the children when the measurement used in the present analysis was taken to calculate weight gain was $13 \cdot 1$ months (range $2 \cdot 1-23 \cdot 8$ months). There were no differences with respect to the mean age for this measurement between children with normal, slow or fast weight gain $(P=0 \cdot 603)$. The mean $Z$-score for growth rate was significantly lower in the children with a negative skin reaction. No differences were found for any of the other outcomes (Fig. 1).

Weight gain in the first two years was considered fast in $29.6 \%$ and slow in $13.9 \%$ of the children. A total of $25.6 \%$ of the children had wheezing in the previous 12 months, $20 \cdot 0 \%$ had asthma symptoms, $31 \cdot 7 \%$ had a positive allergen skin test and $50 \cdot 6 \%$ had a positive test for allergen-specific IgE. We provide the characteristics of the children by weight gain (Table 1 ) and outcome variables (Tables 2 and 3).

Detectable allergen-specific IgE was more frequent in boys and in children who spent the first year of their life in a home in which mould was present (Table 2). A positive skin reaction was statistically more common among children with more highly educated mothers (Table 2).

The prevalence rates for wheezing and asthma symptoms were also significantly greater among children exposed to mould in the home in the first year of life (Table 3). Wheezing and asthma symptoms were significantly more common in children under 6 years of age, in those whose parents reported a history of asthma, in those who had or used to have pets and in those exposed to mould in the home in the first year of life (Table 3 ).

Children aged 4-11 years whose birth weight was $\geq 3500$ g were more likely to have experienced wheezing and asthma symptoms and to have lower predicted values for $\mathrm{FEV}_{1}: \mathrm{FVC}$. $\mathrm{FEV}_{1}: \mathrm{FVC} \leq 98 \%$ was significantly more common among boys, among children whose parents had a history of asthma, among those who had or used to have household pets and among those whose homes were accessed by unpaved streets. A higher proportion of children with $\mathrm{FEV}_{1}: \mathrm{FVC} \leq 98 \%(P<0 \cdot 001)$ and a positive skin test $(P=0.001)$ was observed among overweight children (BMI $Z$-score $\geq+1$; Table 3 ). 

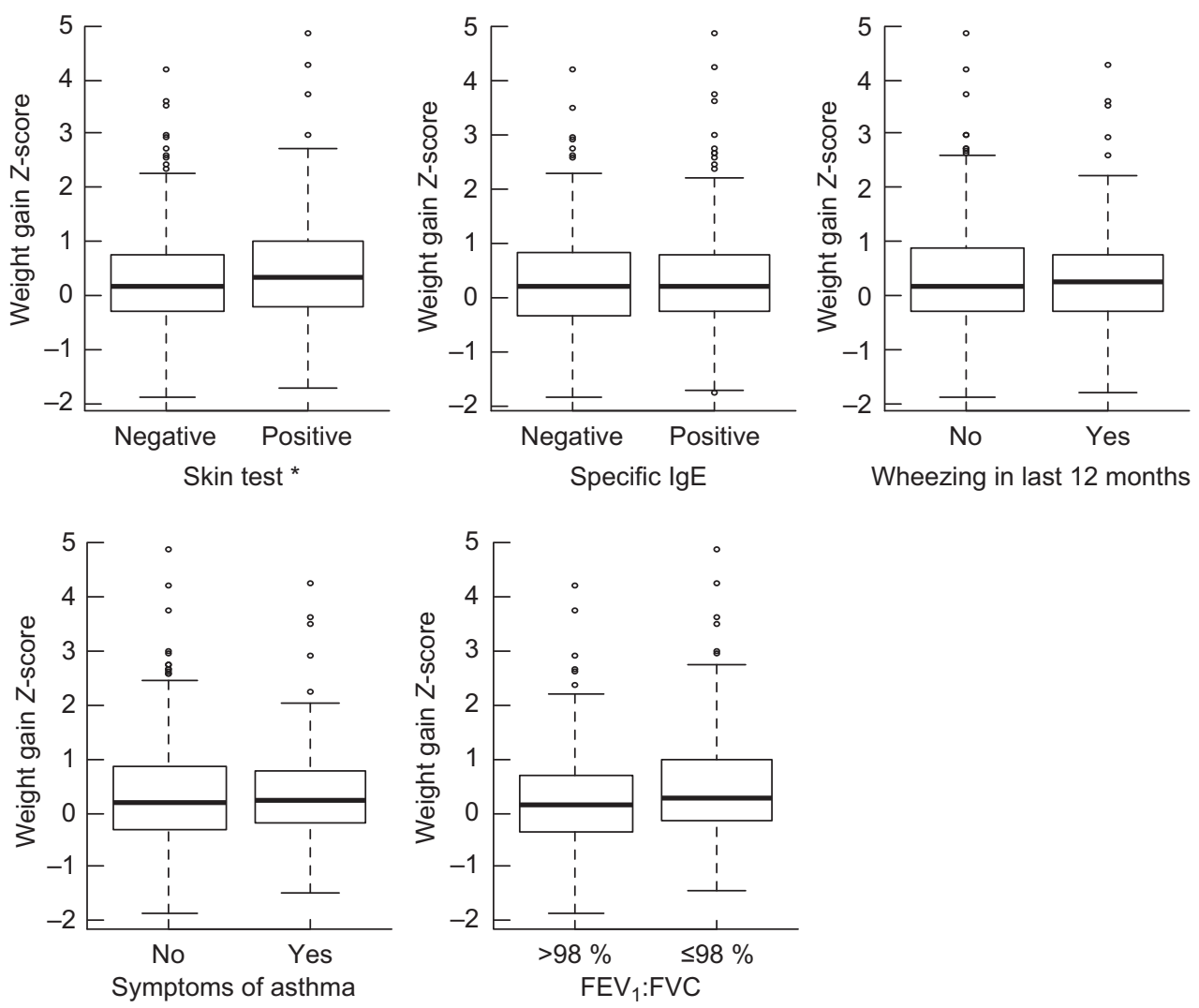

Fig. 1 Box-and-whisker plots showing weight gain Z-scores during the first two years of life according to symptoms of asthma, markers of atopy and pulmonary function in the study population: children ( $n$ 669) aged 4-11 years, Salvador, Bahia, Brazil, 1997-2005. Thick black line within the box indicates the median; the bottom and top of the box represent the 25th and 75th percentile, respectively (interquartile range); the lower and upper whiskers represent the minimum and maximum values; and circles represent outliers (FEV ${ }_{1}$, forced expiratory volume in $1 \mathrm{~s}$; FVC, forced vital capacity). *Weight gain Z-score was significantly different between groups (Student's $t$ test): $P=0.019$

The prevalence of asthma symptoms was reduced by $36 \%$ in the children with slow compared with normal weight gain in multivariate analysis $(\mathrm{PR}=0.65$; 95\% CI 0.42, 0.99; Table 4).

Likelihood ratio tests for interaction were not statistically significant for birth weight, duration of breast-feeding and age for any of the outcomes.

\section{Discussion}

Our main study finding was that slow weight gain in the first two years of life was negatively associated with asthma symptoms in late childhood. We have already shown in this study population that weight gain in the first years of life is associated with BMI at age 4-11 years $^{(22)}$ and that overweight children have an increased risk of asthma symptoms ${ }^{(23)}$. These findings contribute to the body of evidence showing that slow weight gain in the first years of life may not only be a protective factor against becoming overweight but also be protective against asthma. There was no statistically significant association between atopy and weight gain and it is possible that the mechanism involved in asthma is independent of atopy.

Few studies have evaluated the association between somatic growth in early childhood and asthma or lung function at school age or in adulthood ${ }^{(7-9,24-26)}$. Fast growth in early childhood was associated with wheezing ${ }^{(7,24)}$ in scholars. However, in these studies, growth rate was not measured in the same way as done here. This is due to the use of different reference charts, limiting our ability to compare results. Although we observed an association between weight gain and current asthma, we did not see an association with current wheezing in the present study. We believe that our definition for current asthma may better represent true asthma cases than wheezing alone, because these criteria are more specific than wheezing in the last 12 months, the most common criterion used for ISAAC. We used also wheezing in the previous 12 months alone to permit comparability between the studies.

Studies conducted in different populations have shown an effect of weight gain during infancy on pulmonary function in early ${ }^{(10,25)}$ or late ${ }^{(9)}$ life. A prospective study 
Table 1 Characteristics of the study population according to weight gain group: children ( $n$ 669) aged 4-11 years, Salvador, Bahia, Brazil, 1997-2005

\begin{tabular}{|c|c|c|c|c|c|c|c|c|}
\hline \multirow[b]{3}{*}{ Variable } & \multirow[b]{3}{*}{ Category } & \multicolumn{7}{|c|}{ Weight gain ( $n$ 669) } \\
\hline & & \multicolumn{2}{|c|}{$\begin{array}{c}\text { Slow } \\
\text { (n 93; } 13.9 \%)\end{array}$} & \multicolumn{2}{|c|}{$\begin{array}{c}\text { Normal } \\
\text { (n } 378 ; 56.5 \%)\end{array}$} & \multicolumn{2}{|c|}{$\begin{array}{c}\text { Fast } \\
(n 198 ; 29.6 \%)\end{array}$} & \multirow[b]{2}{*}{$P$ value } \\
\hline & & $n$ & $\%$ & $n$ & $\%$ & $n$ & $\%$ & \\
\hline \multirow[t]{2}{*}{ Sex } & Male & 56 & $15 \cdot 5$ & 196 & $54 \cdot 3$ & 109 & $30 \cdot 2$ & $0 \cdot 327$ \\
\hline & Female & 37 & $12 \cdot 0$ & 182 & $59 \cdot 1$ & 89 & $28 \cdot 9$ & \\
\hline \multirow[t]{2}{*}{ Age (years) } & $\geq 6$ & 62 & $14 \cdot 4$ & 243 & $56 \cdot 3$ & 127 & $29 \cdot 4$ & 0.901 \\
\hline & $<6$ & 31 & $13 \cdot 1$ & 135 & $57 \cdot 0$ & 71 & $30 \cdot 0$ & \\
\hline \multirow[t]{2}{*}{ Birth weight $(\mathrm{g})$} & $<3500$ & 64 & $13 \cdot 3$ & 270 & $56 \cdot 0$ & 148 & $30 \cdot 7$ & 0.530 \\
\hline & $\geq 3500$ & 29 & $15 \cdot 5$ & 108 & $57 \cdot 8$ & 50 & $26 \cdot 7$ & \\
\hline \multirow[t]{3}{*}{ Duration of breast-feeding } & Never & 21 & $11 \cdot 7$ & 104 & $57 \cdot 8$ & 55 & $30 \cdot 6$ & $0 \cdot 662$ \\
\hline & $<2$ months & 38 & $16 \cdot 5$ & 124 & $53 \cdot 9$ & 68 & $29 \cdot 6$ & \\
\hline & $\geq 2$ months & 34 & $13 \cdot 1$ & 150 & $57 \cdot 9$ & 75 & $29 \cdot 0$ & \\
\hline \multirow[t]{2}{*}{ No. of older siblings } & None & 26 & $9 \cdot 9$ & 143 & $54 \cdot 6$ & 93 & $35 \cdot 5$ & 0.006 \\
\hline & $\geq 1$ & 67 & $16 \cdot 5$ & 235 & $57 \cdot 7$ & 105 & $25 \cdot 8$ & \\
\hline \multirow[t]{2}{*}{ Parental asthma } & No & 81 & $14 \cdot 1$ & 321 & $55 \cdot 8$ & 173 & $30 \cdot 1$ & 0.682 \\
\hline & Yes & 12 & $12 \cdot 8$ & 57 & $60 \cdot 6$ & 25 & $26 \cdot 6$ & \\
\hline \multirow[t]{2}{*}{ No. of children aged $<5$ years in the household } & $\leq 1$ & 48 & $11 \cdot 8$ & 218 & $53 \cdot 7$ & 140 & $34 \cdot 5$ & 0.002 \\
\hline & $>1$ & 45 & $17 \cdot 1$ & 160 & $60 \cdot 8$ & 58 & $22 \cdot 1$ & \\
\hline \multirow[t]{2}{*}{ No. of persons per room } & $<2$ & 59 & $12 \cdot 1$ & 273 & $55 \cdot 9$ & 156 & $32 \cdot 0$ & 0.020 \\
\hline & $\geq 2$ & 34 & $18 \cdot 8$ & 105 & $58 \cdot 0$ & 42 & $23 \cdot 2$ & \\
\hline \multirow[t]{3}{*}{ Maternal schooling } & High school/university & 15 & $11 \cdot 5$ & 67 & $51 \cdot 1$ & 49 & $37 \cdot 4$ & 0.040 \\
\hline & Secondary education & 48 & $12 \cdot 8$ & 215 & $57 \cdot 2$ & 113 & $30 \cdot 1$ & \\
\hline & Illiterate or primary & 30 & $18 \cdot 5$ & 96 & $59 \cdot 3$ & 36 & $22 \cdot 2$ & \\
\hline \multirow[t]{2}{*}{ Smoking during pregnancy } & No & 80 & $13 \cdot 5$ & 332 & $55 \cdot 9$ & 182 & $30 \cdot 6$ & 0.222 \\
\hline & Yes & 13 & $17 \cdot 3$ & 46 & $61 \cdot 3$ & 16 & $21 \cdot 3$ & \\
\hline \multirow[t]{2}{*}{ Mould in the home in first year of life } & No & 33 & $11 \cdot 5$ & 164 & $56 \cdot 9$ & 91 & $31 \cdot 6$ & $0 \cdot 238$ \\
\hline & Yes & 60 & $15 \cdot 7$ & 214 & $56 \cdot 2$ & 107 & $28 \cdot 1$ & \\
\hline \multirow[t]{2}{*}{ Household pets } & Never had & 38 & $11 \cdot 9$ & 182 & $57 \cdot 2$ & 98 & $30 \cdot 8$ & $0 \cdot 364$ \\
\hline & Has/had & 55 & $15 \cdot 7$ & 196 & $55 \cdot 8$ & 100 & $28 \cdot 5$ & \\
\hline \multirow[t]{2}{*}{ Paved street } & Yes & 46 & $15 \cdot 4$ & 168 & $56 \cdot 2$ & 85 & $28 \cdot 4$ & 0.573 \\
\hline & No & 47 & $12 \cdot 7$ & 210 & $56 \cdot 8$ & 113 & $30 \cdot 5$ & \\
\hline \multirow[t]{3}{*}{ BMI (Z-score)† } & $<-2$ & 28 & $30 \cdot 4$ & 54 & $58 \cdot 7$ & 10 & $10 \cdot 9$ & $<0.001$ \\
\hline & $\geq-2$ and $<+1$ & 59 & $12 \cdot 0$ & 295 & $60 \cdot 1$ & 137 & $27 \cdot 9$ & \\
\hline & $\geq+1$ & 6 & $7 \cdot 0$ & 29 & $33 \cdot 7$ & 51 & $59 \cdot 3$ & \\
\hline
\end{tabular}

Data are presented as number of cases $(n)$ and prevalence (\%).

${ }^{*} P$ value from $\chi^{2}$ test; significant $P$ values indicated in bold font.

tBMI Z-score: $<-2=$ underweight; $\geq-2$ and $<+1=$ normal; $\geq+1=$ overweight/obesity.

conducted in Australia concluded that fast weight gain between the first and the twelfth months of life, particularly in children of low birth weight, was associated with decreased pulmonary function at 12 months and increased symptoms of transient asthma, suggesting an important association between somatic growth and pulmonary function in childhood ${ }^{(25)}$. Likewise, Lucas et al. reported that when weight gain and pulmonary function were evaluated between 5 and 14 weeks of life, higher rates of weight gain were positively associated with impaired pulmonary function ${ }^{(10)}$. Nevertheless, in the study conducted by Hancox et al., weight gain in the first three years of life was positively associated with better pulmonary capacity (functional residual capacity) in young adults ${ }^{(9)}$.

The mechanisms involved in the association between fast growth and impaired pulmonary function are not fully understood. It is known that postnatal catch-up growth, as reflected by higher growth rates, has been documented in children who suffered intra-uterine growth restriction. It is also known that the environmental factors that act pre- and postnatally, particularly towards the end of pregnancy and in the first months of life, may affect alveolar development with possible long-term structural and functional damage. In early pregnancy, environmental factors may impair correct cell division in the airways, leading to abnormalities in programming pulmonary function ${ }^{(27)}$. Nevertheless, in some studies, low birth weight was not a prerequisite for the occurrence of fast growth and subsequent impaired pulmonary function ${ }^{(25)}$. Unfortunately, the effect of low birth weight could not be analysed in the current study sample due to the small number of children with this condition. Another hypothesis is that children with normal birth weight and exposed to a hyperenergetic diet gain weight rapidly, but rapid growth is not accompanied by a parallel improvement in pulmonary function because of defective airways or air space development or the inability of airway growth to keep pace with somatic growth $^{(25)}$. In the present study, conducted in the general population, there were only two children with abnormal lung function $\left(\mathrm{FEV}_{1}: \mathrm{FVC}<80 \%\right)$, limiting our capacity to 
Table 2 Characteristics of the study population according to atopy: children ( $n$ 669) aged 4-11 years, Salvador, Bahia, Brazil, 1997-2005

\begin{tabular}{|c|c|c|c|c|c|c|c|}
\hline \multirow[b]{3}{*}{ Variable } & \multirow[b]{3}{*}{ Category } & \multirow{2}{*}{\multicolumn{3}{|c|}{$\frac{\text { Skin reactivity }(n 644)}{\text { Yes }(n 204 ; 31 \cdot 7 \%)}$}} & \multirow{2}{*}{\multicolumn{3}{|c|}{$\begin{array}{l}\text { IgE }>0.35 \mathrm{kU} / \mathrm{l}(n 635) \\
\text { Positive }(n 321 ; 50 \cdot 6 \%)\end{array}$}} \\
\hline & & & & & & & \\
\hline & & $n$ & $\%$ & $P$ value* & $n$ & $\%$ & $P$ value \\
\hline \multirow[t]{2}{*}{ Sex } & Male & 125 & $35 \cdot 5$ & 0.022 & 191 & $55 \cdot 4$ & 0.008 \\
\hline & Female & 79 & $27 \cdot 1$ & & 130 & $44 \cdot 8$ & \\
\hline \multirow[t]{2}{*}{ Age (years) } & $\geq 6$ & 133 & $32 \cdot 0$ & 0.785 & 209 & $50 \cdot 9$ & 0.838 \\
\hline & $<6$ & 71 & $31 \cdot 0$ & & 112 & $50 \cdot 0$ & \\
\hline \multirow[t]{2}{*}{ Birth weight $(g)$} & $<3500$ & 139 & $30 \cdot 0$ & $0 \cdot 149$ & 230 & $50 \cdot 2$ & 0.787 \\
\hline & $\geq 3500$ & 65 & $35 \cdot 9$ & & 91 & $51 \cdot 4$ & \\
\hline \multirow{3}{*}{ Duration of breast-feeding } & Never & 54 & $31 \cdot 2$ & 0.521 & 87 & $51 \cdot 5$ & 0.926 \\
\hline & $<2$ months & 65 & $29 \cdot 3$ & & 109 & $49 \cdot 6$ & \\
\hline & $\geq 2$ months & 85 & $34 \cdot 1$ & & 125 & $50 \cdot 8$ & \\
\hline \multirow[t]{2}{*}{ No. of older siblings } & None & 86 & $34 \cdot 5$ & $0 \cdot 215$ & 122 & $50 \cdot 2$ & $0 \cdot 891$ \\
\hline & $\geq 1$ & 118 & $29 \cdot 9$ & & 199 & $50 \cdot 8$ & \\
\hline \multirow{2}{*}{ Parental asthma } & No & 177 & $31 \cdot 8$ & 0.829 & 277 & $50 \cdot 5$ & 0.903 \\
\hline & Yes & 27 & $30 \cdot 7$ & & 44 & $51 \cdot 2$ & \\
\hline \multirow[t]{2}{*}{ No. of children aged $<5$ years in the household } & $\leq 1$ & 133 & $34 \cdot 1$ & $0 \cdot 101$ & 190 & $49 \cdot 6$ & 0.558 \\
\hline & $>1$ & 71 & $28 \cdot 0$ & & 131 & $52 \cdot 0$ & \\
\hline \multirow[t]{2}{*}{ No. of persons per room } & $<2$ & 164 & $35 \cdot 0$ & 0.003 & 238 & $51 \cdot 6$ & $0 \cdot 378$ \\
\hline & $\geq 2$ & 40 & $22 \cdot 7$ & & 83 & $47 \cdot 7$ & \\
\hline \multirow[t]{3}{*}{ Maternal schooling } & High school/university & 52 & $43 \cdot 0$ & 0.012 & 70 & $57 \cdot 4$ & $0 \cdot 164$ \\
\hline & Secondary education & 106 & $28 \cdot 7$ & & 171 & $47 \cdot 6$ & \\
\hline & Illiterate or primary & 46 & $29 \cdot 9$ & & 80 & $52 \cdot 0$ & \\
\hline \multirow[t]{2}{*}{ Smoking during pregnancy } & No & 183 & $32 \cdot 0$ & 0.570 & 287 & $51 \cdot 0$ & 0.548 \\
\hline & Yes & 21 & $28 \cdot 8$ & & 34 & $47 \cdot 2$ & \\
\hline \multirow[t]{2}{*}{ Mould in the house in the first year of life } & No & 78 & $28 \cdot 6$ & $0 \cdot 146$ & 125 & $46 \cdot 1$ & 0.054 \\
\hline & Yes & 126 & $34 \cdot 0$ & & 196 & $53 \cdot 8$ & \\
\hline \multirow[t]{2}{*}{ Household pets } & Never had & 109 & $35 \cdot 2$ & 0.067 & 156 & $50 \cdot 6$ & 0.962 \\
\hline & Has/had & 95 & $28 \cdot 4$ & & 165 & $50 \cdot 5$ & \\
\hline \multirow[t]{2}{*}{ Paved street } & Yes & 97 & $34 \cdot 3$ & 0.209 & 153 & $54 \cdot 4$ & 0.080 \\
\hline & No & 107 & $29 \cdot 6$ & & 168 & $47 \cdot 5$ & \\
\hline \multirow[t]{3}{*}{ BMI (Z-score)† } & $<-2$ & 22 & $25 \cdot 3$ & 0.001 & 39 & $45 \cdot 9$ & $0 \cdot 157$ \\
\hline & $\geq-2$ and $<+1$ & 142 & $29 \cdot 9$ & & 234 & $49 \cdot 8$ & \\
\hline & $\geq+1$ & 40 & $48 \cdot 8$ & & 48 & $60 \cdot 0$ & \\
\hline
\end{tabular}

Data are presented as number of cases $(n)$ and prevalence (\%).

${ }^{\star} P$ value from $\chi^{2}$ test; significant $P$ values indicated in bold font.

tBMI Z-score: $<-2=$ underweight; $\geq-2$ and $<+1=$ normal; $\geq+1=$ overweight/obesity.

detect differences between weight gain and impairment in lung function.

There is evidence that children who experience postnatal catch-up growth are more likely to be obese at 5 years of age than children with normal growth $^{(1)}$, and high levels of serum insulin and leptin have also been found in overweight children. Leptin is an adiposederived hormone whose inflammatory effect may alter the balance of Th1 and Th2 cytokines in obese individuals by affecting Th1 cell differentiation and the production of pro-inflammatory cytokines such as TNF- $\alpha$. Thus, high levels of serum leptin could be associated with the pathogenesis of asthma in overweight children ${ }^{(5,28-30)}$ by the induction of a pro-inflammatory state in which inflammation in the airways may be increased, leading to alterations in pulmonary physiology. In the population of children studied here, overweight was less frequent among those with a slow weight gain ${ }^{(22)}$. It is possible that that lower leptin levels may have been present in these children and, consequently, they may have had a lower risk of wheezing and asthma. This hypothesis will need to be tested in future studies that measure levels of serum leptin.
Some limitations present in previous studies were not an issue in our study. In our study, prospective data were obtained directly from the children's parents or guardians. In addition, sample size was adequate and the same methodology was used for data collection from baseline onwards, with most of the members of the technical field team remaining throughout the entire project. The availability data for of total and allergen-specific $\operatorname{IgE}$ and spirometry was a strength compared with previous studies conducted under similar conditions and with similar populations. We were also able to control our analyses for multiple socio-economic, environmental and other confounding factors related to the health of the child and to the exposure and outcomes. A limitation is that it is not possible to make inferences on causality because data on the study outcomes were not obtained in infancy, thereby not allowing us to distinguish between those who did and did not have study outcomes at baseline. Beyond this, another limitation is that we did not have the total of children evaluated for outcomes in 2005 with anthropometric outcomes (weight gain) collected in infancy. The baseline of the cohort about asthma was in 2005 and on this occasion 1445 children were sorted by three previous 
Table 3 Characteristics of the study population according to variables related with current asthma: children ( $n$ 669) aged 4-11 years, Salvador, Bahia, Brazil, 1997-2005

\begin{tabular}{|c|c|c|c|c|c|c|c|c|c|c|}
\hline \multirow[b]{3}{*}{ Variable } & \multirow[b]{3}{*}{ Category } & \multirow{2}{*}{\multicolumn{3}{|c|}{$\begin{array}{c}\text { Wheezing in previous } 12 \text { months }(n 669) \\
\text { Yes }(n 171 ; 25 \cdot 6 \%)\end{array}$}} & \multirow{2}{*}{\multicolumn{3}{|c|}{$\begin{array}{c}\text { Asthma symptoms }(n 669) \\
\text { Yes }(n 134 ; 20 \cdot 0 \%)\end{array}$}} & \multirow{2}{*}{\multicolumn{3}{|c|}{$\begin{array}{l}\text { FEV }_{1}: \text { FVC }(n 508) \\
\leq 98 \%(n 218 ; 42.9 \%)\end{array}$}} \\
\hline & & & & & & & & & & \\
\hline & & $n$ & $\%$ & $P$ value* & $n$ & $\%$ & $P$ value $^{\star}$ & $n$ & $\%$ & $P$ value* \\
\hline \multirow[t]{2}{*}{ Sex } & Male & 93 & $25 \cdot 8$ & 0.897 & 72 & $19 \cdot 9$ & 0.952 & 135 & $50 \cdot 2$ & 0.000 \\
\hline & Female & 78 & $25 \cdot 3$ & & 62 & $20 \cdot 1$ & & 83 & $34 \cdot 7$ & \\
\hline \multirow[t]{2}{*}{ Age (years) } & $\geq 6$ & 89 & $20 \cdot 6$ & $<0.001$ & 73 & $16 \cdot 9$ & 0.006 & 139 & $42 \cdot 0$ & 0.567 \\
\hline & $<6$ & 82 & $34 \cdot 6$ & & 61 & $25 \cdot 7$ & & 79 & $44 \cdot 6$ & \\
\hline \multirow[t]{2}{*}{ Birth weight $(g)$} & $<3500$ & 113 & $23 \cdot 4$ & 0.044 & 87 & $18 \cdot 0$ & 0.040 & 141 & $39 \cdot 9$ & 0.041 \\
\hline & $\geq 3500$ & 58 & $31 \cdot 0$ & & 47 & $25 \cdot 1$ & & 77 & $49 \cdot 7$ & \\
\hline \multirow[t]{3}{*}{ Duration of breast-feeding } & Never & 52 & $28 \cdot 9$ & $0 \cdot 168$ & 41 & $22 \cdot 8$ & 0.205 & 80 & $41 \cdot 0$ & 0.597 \\
\hline & $<2$ months & 63 & $27 \cdot 4$ & & 50 & $21 \cdot 7$ & & 58 & $41 \cdot 7$ & \\
\hline & $\geq 2$ months & 56 & $21 \cdot 6$ & & 43 & $16 \cdot 6$ & & 80 & $46 \cdot 0$ & \\
\hline \multirow[t]{2}{*}{ No. of older siblings } & None & 58 & $22 \cdot 1$ & $0 \cdot 103$ & 45 & $17 \cdot 2$ & $0 \cdot 139$ & 92 & $46 \cdot 7$ & $0 \cdot 170$ \\
\hline & $\geq 1$ & 113 & $27 \cdot 8$ & & 89 & $21 \cdot 9$ & & 126 & $40 \cdot 5$ & \\
\hline \multirow[t]{2}{*}{ Parental asthma } & No & 137 & $23 \cdot 8$ & 0.011 & 104 & $18 \cdot 1$ & 0.002 & 176 & $40 \cdot 4$ & 0.004 \\
\hline & Yes & 34 & $36 \cdot 2$ & & 30 & $31 \cdot 9$ & & 42 & $58 \cdot 3$ & \\
\hline \multirow[t]{2}{*}{ No. of children aged $<5$ years of age in the household } & $\leq 1$ & 92 & $22 \cdot 7$ & 0.033 & 75 & $18 \cdot 5$ & $0 \cdot 211$ & 131 & $42 \cdot 7$ & 0.892 \\
\hline & $>1$ & 79 & $30 \cdot 0$ & & 59 & $22 \cdot 4$ & & 87 & $43 \cdot 3$ & \\
\hline \multirow{2}{*}{ No. of persons per room } & $<2$ & 123 & $25 \cdot 2$ & 0.729 & 96 & $19 \cdot 7$ & 0.704 & 165 & $44 \cdot 7$ & $0 \cdot 181$ \\
\hline & $\geq 2$ & 48 & $26 \cdot 5$ & & 38 & $21 \cdot 0$ & & 53 & $38 \cdot 1$ & \\
\hline \multirow[t]{3}{*}{ Maternal schooling } & High school/university & 34 & $26 \cdot 0$ & 0.883 & 25 & $19 \cdot 1$ & $0 \cdot 767$ & 45 & $47 \cdot 9$ & 0.509 \\
\hline & Secondary education & 98 & $26 \cdot 1$ & & 79 & $21 \cdot 0$ & & 120 & $41 \cdot 1$ & \\
\hline & Illiterate or primary & 39 & $24 \cdot 1$ & & 30 & $18 \cdot 5$ & & 53 & $43 \cdot 4$ & \\
\hline \multirow[t]{2}{*}{ Smoking during pregnancy } & No & 149 & $25 \cdot 1$ & 0.427 & 117 & $19 \cdot 7$ & 0.545 & 194 & $42 \cdot 9$ & 0.993 \\
\hline & Yes & 22 & $29 \cdot 3$ & & 17 & $22 \cdot 7$ & & 24 & $42 \cdot 9$ & \\
\hline \multirow[t]{2}{*}{ Mould in the house in the first year of life } & No & 54 & $18 \cdot 8$ & $<0.001$ & 40 & $13 \cdot 9$ & 0.001 & 86 & $40 \cdot 6$ & 0.366 \\
\hline & Yes & 117 & $30 \cdot 7$ & & 94 & $24 \cdot 7$ & & 132 & $44 \cdot 6$ & \\
\hline \multirow[t]{2}{*}{ Household pets } & Never had & 67 & $21 \cdot 1$ & 0.011 & 52 & $16 \cdot 4$ & 0.024 & 89 & $37 \cdot 9$ & 0.033 \\
\hline & Has/had & 104 & $29 \cdot 6$ & & 82 & $23 \cdot 4$ & & 129 & $47 \cdot 3$ & \\
\hline \multirow[t]{2}{*}{ Paved street } & Yes & 69 & $23 \cdot 1$ & $0 \cdot 186$ & 52 & $17 \cdot 4$ & $0 \cdot 125$ & 79 & $36 \cdot 1$ & 0.007 \\
\hline & No & 102 & $27 \cdot 6$ & & 82 & $22 \cdot 2$ & & 139 & $48 \cdot 1$ & \\
\hline \multirow[t]{3}{*}{ BMI (Z-score) +} & $<-2$ & 17 & $18 \cdot 5$ & $0 \cdot 176$ & 14 & $15 \cdot 2$ & $0 \cdot 152$ & 16 & $25 \cdot 4$ & 0.000 \\
\hline & $\geq-2$ and $<+1$ & 128 & $26 \cdot 1$ & & 97 & $19 \cdot 8$ & & 163 & $42 \cdot 9$ & \\
\hline & $\geq+1$ & 26 & $30 \cdot 2$ & & 23 & $26 \cdot 7$ & & 39 & $60 \cdot 0$ & \\
\hline
\end{tabular}

$\mathrm{FEV}_{1}$, forced expiratory volume in $1 \mathrm{~s}$; FVC, forced vital capacity.

Data are presented as number of cases $(n)$ and prevalence $(\%)$.

tBMI Z-score: $<-2=$ underweight; $\geq-2$ and $<+1=$ normal; $\geq+1=$ overweight/obesity. 
Table 4 Prevalence and prevalence ratio of the study end points according to the speed of weight gain (in Z-scores) during the first two years of life: children ( $n$ 669) aged 4-11 years, Salvador, Bahia, Brazil, 1997-2005

\begin{tabular}{|c|c|c|c|c|c|c|}
\hline End point/weight gain* & $n$ & $\%$ & PRt & $95 \% \mathrm{Cl}$ & PR $\ddagger$ & $95 \% \mathrm{Cl}$ \\
\hline \multicolumn{7}{|l|}{ Symptoms of asthma } \\
\hline Slow & 13 & $14 \cdot 0$ & 0.66 & $0.41,1.05$ & 0.65 & $0.42,0.99$ \\
\hline Normal & 80 & $21 \cdot 2$ & $1 \cdot 00$ & - & $1 \cdot 00$ & - \\
\hline Fast & 41 & $20 \cdot 7$ & 0.98 & $0.71,1 \cdot 34$ & $1 \cdot 00$ & $0 \cdot 71,1 \cdot 40$ \\
\hline \multicolumn{7}{|c|}{ Wheezing in the previous 12 months } \\
\hline Slow & 20 & $21 \cdot 5$ & $0 \cdot 79$ & $0 \cdot 52,1 \cdot 19$ & $0 \cdot 80$ & $0 \cdot 55,1 \cdot 15$ \\
\hline Normal & 103 & $27 \cdot 2$ & $1 \cdot 00$ & - & $1 \cdot 00$ & - \\
\hline Fast & 48 & $24 \cdot 2$ & $0 \cdot 89$ & $0 \cdot 66,1 \cdot 20$ & $0 \cdot 91$ & $0 \cdot 67,1 \cdot 25$ \\
\hline \multicolumn{7}{|c|}{ Forced expiratory ratio $\left(\mathrm{FEV}_{1}: \mathrm{FVC}\right)$} \\
\hline Slow & 26 & $39 \cdot 4$ & 0.96 & $0 \cdot 75,1 \cdot 22$ & $1 \cdot 00$ & $0.80,1 \cdot 26$ \\
\hline Normal & 122 & $41 \cdot 1$ & $1 \cdot 00$ & - & $1 \cdot 00$ & - \\
\hline Fast & 70 & $48 \cdot 3$ & $1 \cdot 17$ & $0.92,1.50$ & 1.05 & $0.80,1.38$ \\
\hline \multicolumn{7}{|l|}{ Skin reactivity to allergens } \\
\hline Slow & 24 & $26 \cdot 4$ & $0 \cdot 86$ & $0.56,1.35$ & $0 \cdot 86$ & $0.57,1.30$ \\
\hline Normal & 110 & $30 \cdot 5$ & $1 \cdot 00$ & - & $1 \cdot 00$ & - \\
\hline Fast & 70 & $36 \cdot 5$ & $1 \cdot 20$ & $0.91,1.56$ & $1 \cdot 07$ & $0.81,1 \cdot 42$ \\
\hline \multicolumn{7}{|c|}{ IgE detectable for allergens } \\
\hline Slow & 47 & $52 \cdot 2$ & $1 \cdot 05$ & $0 \cdot 85,1 \cdot 30$ & $1 \cdot 02$ & $0 \cdot 81,1 \cdot 30$ \\
\hline Normal & 177 & $49 \cdot 9$ & $1 \cdot 00$ & - & $1 \cdot 00$ & - \\
\hline Fast & 97 & $51 \cdot 1$ & $1 \cdot 02$ & $0 \cdot 88,1 \cdot 19$ & 0.98 & $0 \cdot 82,1 \cdot 16$ \\
\hline
\end{tabular}

$n$, number of cases; PR, prevalence ratio; $\mathrm{FEV}_{1}$, forced expiratory volume in $1 \mathrm{~s}$; FVC, forced vital capacity.

Significant associations are indicated in bold font.

${ }^{*}$ Weight gain: slow $=Z$-score $<-0.67$; normal $=Z$-score $\geq-0.67$ to $\leq 0.67$; fast $=Z$-score $>0.67$.

tCrude prevalence ratio.

¥Prevalence ratio adjusted for sex, age, maternal schooling, parental asthma, birth weight, duration of breast-feeding, smoking during pregnancy, mould in the house in the first year of life, BMI, number of older siblings, household pets, number of persons per room, number of children aged $<5$ years in the household and paving in the street.

cohorts, but we have previous information about weight gain on only 669 children. In this cohort of a low-income community, it was not feasible to follow up each individual in the cohort periodically to evaluate study outcomes, although it is difficult to predict at what age such outcomes might be predicted to appear in childhood.

\section{Conclusion}

Our findings suggest that in a population of children living in poor neighbourhoods in a Latin American city, slow weight gain in infancy may be protective against asthma. Since asthma and obesity are problems that begin in pre-schoolers, interventions to maintain adequate weight but avoid excessive weight gain in early infancy could have several benefits including a reduction in asthma symptoms in late childhood.

\section{Acknowledgements}

Sources offunding: The present study was funded by The Wellcome Trust, UK under the HCPC Latin America Excellence Centre Programme (Ref. 072405/Z/03/Z). The previous studies conducted with the same cohort were supported by the Programa de Núcleo de Excelência (PRONEX-CNPq/MCT), Brazil (Contract no. 66.1086/ 1998-4) and by the Bahia State Government Department of Urban Development, Brazil. S.d.M.S. was supported by the Foundation for the Support of Research in the State of
Bahia (FAPESB), Brazil (1941/2006). Conflicts of interest: The authors have no conflict of interest to declare. Ethics: Ethical approval for this study was provided by the Internal Review Board of the Institute of Collective Health, Federal University of Bahia, by the National Commission on Ethics in Research (CONEP), Brazil, and by the London School of Hygiene and Tropical Medicine. Authors' contributions: S.M.A.M. was responsible for writing this manuscript; M.L.B., L.C.R. and A.A.C. obtained the funding and coordinated the study; M.S.P. and M.L.B. designed the methodology for data collection; M.S.P. coordinated and S.M.A.M. participated in collecting the anthropometric data; S.d.M.S. supervised and participated in collecting the spirometry test data; N.M.A.-N. supervised the detection of IgE antibodies; S.R.J., S.M.A.M., R.L.F. and S.R.D.M.S. conducted the statistical analyses; A.M.O.A., S.M.A.M., A.A.C. and S.D.I. contributed by critically reviewing the manuscript. All authors contributed to reviewing the manuscript and are in agreement with respect to its submission. Acknowledgements: The authors wish to express their gratitude to the children and parents who participated in this study. They also thank Dr Philip J. Cooper for review of the manuscript.

\section{References}

1. Ong KK, Ahmed ML, Emmett PM et al. (2000) Association between postnatal catch-up growth and obesity in childhood: prospective cohort study. BMJ 320, 967-971. 
2. Barker DJP, Osmond C, Forsen TJ et al. (2005) Trajectories of growth among children who have coronary events as adults. $N$ Engl J Med 353, 1802-1809.

3. Briana DD \& Malamitsi-Puchner A (2009) Intrauterine growth restriction and adult disease: the role of adipocytokines. Eur J Endocrinol 160, 337-347.

4. Monteiro POA \& Victora CG (2005) Rapid growth in infancy and childhood and obesity in later life - a systematic review. Obes Rev 6, 143-154.

5. Tantisira KG \& Weiss ST (2001) Complex interactions in complex traits: obesity and asthma. Thorax 56, 64-74.

6. Mai XM, Gaddlin PO, Nilsson L et al. (2003) Asthma, lung function and allergy in 12-year-old children with very low birth weight: a prospective study. Pediatr Allergy Immunol 14, 184-192.

7. Rona RJ, Smeeton NC, Bustos P et al. (2005) The early origins hypothesis with an emphasis on growth rate in the first year of life and asthma: a prospective study in Chile. Thorax 60, 549-554.

8. Flaherman V \& Rutherford GW (2006) A meta-analysis of the effect of high weight on asthma. Arch Dis Child $\mathbf{9 1}$, 334-339.

9. Hancox RJ, Poulton R, Greene JM et al. (2009) Associations between birth weight, early childhood weight gain, and adult lung function. Thorax 64, 228-232.

10. Lucas JS, Inskip HM, Godfrey KM et al. (2004) Small size at birth and greater postnatal weight gain relationships to diminished infant lung function. Am J Respir Crit Care Med 170, 534-540.

11. Barreto ML, Genser B, Strina A et al. (2007) Effect of city-wide sanitation programme on reduction in rate of childhood diarrhoea in northeast Brazil: assessment by two cohort studies. Lancet 9599, 1622-1628.

12. Prado MS, Cairncross S, Strina A et al. (2005) Asymptomatic giardiasis and growth in young children; a longitudinal study in Salvador, Brazil. Parasitology 131, 51-56.

13. Organización Mundial de la Salud (1995) El estado físico: uso e interpretación de la antropometría. Série de Informes Técnicos no. 854. Ginebra: OMS.

14. Monteiro POA, Victora CG, Barros FC et al. (2003) Birth size, early childhood growth, and adolescent obesity in a Brazilian birth cohort. Int J Obes Relat Metab Disord 27, 1274-1282.

15. Cameron N, Pettifor J, De Wet T et al. (2003) The relationship of rapid weight gain in infancy to obesity and skeletal maturity in childhood. Obes Res 11, 457-460.

16. Barreto ML, Cunha SS, Alcântara NN et al. (2006) Risk factors and immunological pathways for asthma and other allergic disease in children: background and methodology of a longitudinal study in a large urban center in
Northeastern Brazil (Salvador-SCAALA study). BMC Pulm Med 6, 15.

17. Miller MR, Hankinson J, Brusasco V et al. (2005) Standardisation of spirometry. Eur Respir J 26, 319-338.

18. Rodrigues JC, Cardieri JMA, Bussamra MHCF et al. (2002) Provas de função pulmonar em crianças e adolescentes. J Pneumol 28, Suppl. 3, 207-221.

19. Pereira CAC (2002) Espirometria. Consenso Brasileiro de Avaliação da Função Pulmonar. J Pneumol 28, Suppl. 3, $1-8$.

20. Barros A \& Hirakata V (2003) Alternatives for logistic regression in cross-sectional studies: an empirical comparison of models that directly estimate the prevalence ratio. BMC Med Res Methodol 3, 21.

21. Rothman KJ \& Greenland S (1998) Modern Epidemiology. Philadelphia, PA: Lippincott-Raven Publications.

22. Matos SMA, Jesus SR, Saldiva SRDM et al. (2011) Velocidade de ganho de peso nos primeiros anos de vida e excesso de peso entre 5-11 anos de idade, Salvador, Bahia. Cad Saude Publica 27, 714-722.

23. Matos SMA, Jesus SR, Saldiva SRDM et al. (2011) Overweight, asthma symptoms, atopy and pulmonary function in children of 4 to 12 years of age: findings from the SCAALA cohort in Salvador, Bahia, Brazil. Public Health Nutr 14, 1270-1278.

24. Taveras EM, Rifas-Shiman SL, Camargo CA Jr et al. (2008) Higher adiposity in infancy associated with recurrent wheeze in a prospective cohort of children. J Allergy Clin Immunol 21, 1161-1166.

25. Turner S, Zhang G, Young S et al. (2008) Associations between postnatal weight gain, change in postnatal pulmonary function, formula feeding and early asthma. Thorax 63, 234-239.

26. Mai XM, Gaddlin PO, Nilsson L et al. (2005) Early rapid weight gain and current overweight in relation to asthma in adolescents born with very low birth weight. Pediatr Allergy Immunol 16, 380-385.

27. Maritz GS, Colin J, Morley B et al. (2005) Early developmental origins of impaired lung structure and function. Early Hum Dev 81, 763-771.

28. Al-Shawwa B, Al-Huniti N, Titus G et al. (2006) Hypercholesterolemia is a potential risk factor for asthma. J Asthma 43, 231-233.

29. Matsuda K, Nishi Y, Okamatsu Y et al. (2006) Ghrelin and leptin: a link between obesity and allergy? J Allergy Clin Immunol 117, 705-706.

30. Mai XM, Böttcher MF \& Leijon I (2004) Leptin and asthma in overweight children at 12 years of age. Pediatr Allergy Immunol 15, 523-530. 